\title{
Dexamethasone and lenvatinib inhibit migration and invasion of non-small cell lung cancer by regulating EKR/AKT and VEGF signal pathways
}

\author{
DAYE ZHANG ${ }^{1}$, YONGXIANG ZHANG ${ }^{2}$, ZEYUAN CAI $^{3}$, YING TU $^{1}$ and ZHANSONG HU ${ }^{1}$ \\ ${ }^{1}$ Department of Pharmacy; ${ }^{2}$ Respiratory and Clinical Care Unit; ${ }^{3}$ Department of Cardiovascular Institute, \\ Tianjin Chest Hospital, Tianjin 300222, P.R. China
}

Received February 14, 2016; Accepted February 24, 2017

DOI: $10.3892 /$ etm.2019.8225

\begin{abstract}
Migration and invasion is one of the most important features in tumor metastasis and development. Non-small cell lung cancer (NSCLC) is one of the most common types of cancer globally, and has been linked to air contamination. Evidence indicates that cysteine-rich angiogenic inducer 61 (CYR61) is associated with the migration and invasion of NSCLC. Overexpression of CYR61 protein promotes the migration and the transition of tumor-derived vascular endothelial cells in NSCLC. However, the association between CYR61 and NSCLC remains poorly understood. Lenvatinib is an oral multi-target drug that targets various receptors upon tumor angiogenesis. Dexamethasone is widely approved for combination therapy in patients with NSCLC. In the current study, the expression and function of CYR61 in NSCLC was analyzed during the progression of NSCLC. Inhibitory effects on migration and invasion induced by lenvatinib and dexamethasone were determined by migratory and invasion assays. Migratory pathways of extracellular signal-regulated kinases (ERK) and protein kinase B (AKT) were also investigated by targeting vascular endothelial growth factor (VEGF) and CYR61 via synergistic treatment with transforming growth factor- $\beta 1$ (TGF- $\beta 1$ ) and dexamethasone. Therapeutic outcomes of combined treatment with lenvatinib and dexamethasone were assessed in NSCLC-bearing mice. The results of the present study indicate that cooperative treatment of lenvatinib and dexamethasone significantly inhibited TGF- $\beta 1$-induced cell migration and suppressed tumor growth $(\mathrm{P}<0.01)$. Notably, the results demonstrated that dexamethasone eradicated the promotion effects of TGF- $\beta 1$ on the AKT/epithelial-mesenchymal transition process and lenvatinib extinguished tumor
\end{abstract}

Correspondence to: Professor Daye Zhang, Department of Pharmacy, Tianjin Chest Hospital, 261 Taierzhuang Road, Jinnan, Tianjin 300222, P.R. China

E-mail: zhangdayeedu@163.com

Key words: dexamethasone, lenvatinib, cysteine-rich protein 61, vascular endothelial growth factor, non-small cell lung cancer cell metastasis by targeting VEGF. The results of the current study also demonstrate that dexamethasone suppressed the expression of CAG-I and enhanced expression of matrix metalloproteinase-1. Synergistic treatment for NSCLC was demonstrated to be efficacious. In conclusion, dexamethasone inhibited AKT/ERK phosphorylation and lenvatinib antagonism bound VEGF leading to the limitation of migration and invasion of cancer cells in NSCLC.

\section{Introduction}

Lung cancer is a respiratory disease, which is associated with global air contamination (1). Non-small cell lung cancer (NSCLC) is a type of cancer that initiates in the non-small cells of the lung and occupies the highest occurrence rate among all cancer cases (2). NSCLC, including squamous cell carcinoma, large cell carcinoma and adenocarcinoma, accounts for $>80 \%$ of all lung cancer cases (3-5). Although studies have provided therapeutic improvements for NSCLC, the poor survival rate (overall 5-year survival rate, $<15 \%$ ) of patients with NSCLC is primarily attributed to critical clinical problems, including tumor cell diffusion and metastasis $(4,6,7)$. Migration and invasion of NSCLC is the primary cause of the poor survival rate during treatment and recurrence for patients with NSCLC $(8,9)$. Therefore, investigating effective agents that inhibit migration and invasion and providing individualized medication for NSCLC has become the focus for treating patients with cancer $(10,11)$.

Lenvatinib is a multi-targeted tyrosine kinase inhibitor targeting fibroblast growth factor receptor (FGFR)1-4, platelet derived growth factor receptor (PDGFR)- $\beta$, Ret, vascular endothelial growth factor receptor (VEGFR)1-3 and Kit and is used to treat patients $(12,13)$. PDGFR- $\beta$, Ret, FGFR1-4, VEGF and Kit-mediated angiogenesis have been demonstrated to target molecules associated with the progression and neoplasm metastasis of NSCLC (14). In addition, the antitumor activities of lenvatinib against various human tumors have been assessed in clinical and preclinical experiments to confirm efficacy $(15,16)$. Target agents that suppressed the VEGF signal pathway have demonstrated beneficial outcomes in NSCLC, which suggests that the VEGF signal pathway is important and lenvatinib is an effective anticancer drug (17). Furthermore, 
lenvatinib has also demonstrated clinical benefits via the targeting of PDGFR- $\beta$, Ret, VEGFR1-3, FGFR1-4 and Kit pathways in metastatic renal cell carcinoma $(18,19)$. A previous study indicated that lenvatinib administration with carboplatin and paclitaxel extended the overall survival in patients with NSCLC (14). However, the association between lenvatinib and migration and invasion remains unknown.

Dexamethasone is commonly applied as an anti-emetic drug in combination with chemotherapy. A previous study evaluated the pharmacokinetics and safety of drugs combined with dexamethasone in patients with multiple myeloma and renal impairment (20). Han et al (21) reported that dexamethasone inhibited transforming growth factor (TGF)- $\beta 1$-induced cell migration by regulating the extracellular signal-regulated kinases (ERK) and protein kinase B (AKT) pathways in human colon cancer cells via the cysteine-rich angiogenic inducer 61 (CYR61). CYR61 is a member of the CYR61/connective tissue growth factor/nephroblastoma overexpressed protein family, which is mediated in cellular adhesion, survival, migration, mitogenesis, differentiation, proliferation, invasion, survival and angiogenesis and the metastasis of cancer cells (22). CYR61 may have an essential role as an oncogene and a tumor suppressor for suppressing angiogenesis by supplying oxygen and nutrients to tumor cells (23).

The aim of the present study was to elucidate the molecular mechanism of migration and invasion in NSCLC progression and investigate the synergistic effects of TGF and dexamethasone on NSCLC for improved therapy. In addition, the therapeutic outcomes and molecular mechanism were investigated via cooperative treatment with lenvatinib and dexamethasone, which inhibited human NSCLC migration and invasion via mediated EKR/AKT and VEGF signaling pathways.

\section{Materials and methods}

Cell culture. H1975 and H358 cells were purchased from American Type Culture Collection (Manassas, VA,USA).H1975 and H358 cells were cultured in RPMI 1640 medium supplemented with $10 \%$ fetal bovine serum (FBS; Gibco; Thermo Fisher Scientific, Inc., Waltham, MA, USA) at $37^{\circ} \mathrm{C}$ in an atmosphere containing 5\% $\mathrm{CO}_{2}$ and reasonable humidity (45-60\%).

MTT assay for viability. $\mathrm{H} 1975$ and H358 cells were cultured in 96-well plates to form a $~ 90 \%$ monolayer. Subsequently, dexamethasone, TGF- $\beta 1(20,40$ and $100 \mathrm{mg} / \mathrm{ml})$, lenvatinib (20, 40 and $100 \mathrm{mg} / \mathrm{ml})$ or dexamethasone $(20,40$ and $100 \mathrm{mg} / \mathrm{ml}$ plus TGF- $\beta 1(20,40$ and $100 \mathrm{mg} / \mathrm{ml})$ were added into cells for $12 \mathrm{~h}$ at $37^{\circ} \mathrm{C}$ (all Sigma-Aldrich; Merck KGaA, Darmstadt, Germany). A total of $10 \mu \mathrm{l}$ MTT at a concentration of $5 \mathrm{mg} / \mathrm{ml}$ (Amresco LLC, Solon, OH, USA) was added to the cells and incubated for $4 \mathrm{~h}$ at $37^{\circ} \mathrm{C}$. Subsequently, dimethyl sulfoxide was added for incubation for $30 \mathrm{~min}$ at $37^{\circ} \mathrm{C}$ to dissolve the precipitate, following the removal of the supernatant. The results were determined using a spectrophotometer (Bio-Rad Laboratories, Inc., Hercules, CA, USA) at $570 \mathrm{~nm}$.

Reverse transcription-quantitative polymerase chain reaction (RT-qPCR). Total RNA was isolated from H1975 and H358 cells prior to or following treatment with TGF- $\beta 1$, lenvatinib or dexamethasone using an RNAeasy Mini kit (Qiagen Sciences,
Inc., Gaithersburg, MD, USA). Total RNA (1 $\mu \mathrm{g})$ was reverse transcribed into cDNA using an RT kit (Qiagen Sciences, Inc.) and the quality was confirmed by $2 \%$ agarose gel electrophoresis. Template cDNA (10 ng) was subjected to qPCR using a SYBR Green Master Mix (Bio-Rad Laboratories, Inc.). PCR was performed using the following conditions: Preliminary denaturation at $94^{\circ} \mathrm{C}$ for 2 min, 45 cycles of $94^{\circ} \mathrm{C}$ for $30 \mathrm{sec}$, the annealing temperature was reduced to $56^{\circ} \mathrm{C}$ for $30 \mathrm{sec}$ and a final step of $72^{\circ} \mathrm{C}$ for $10 \mathrm{~min}$. All the forward and reverse primers were synthesized by Invitrogen (Table I) (Thermo Fisher Scientific, Inc.). Relative mRNA expression changes were calculated according to the $2^{-\Delta \Delta \mathrm{Cq}}$ method (24). Results were expressed as the $n$-fold $\beta$-actin compared with the relative control.

Cell viability assay. H1975 and H358 cells were cultured in 24-well plates at a concentration of $1 \times 10^{6} / \mathrm{ml}$ and a total column volume of $500 \mu \mathrm{l}$. Following overnight culture, H1975 and H358 cells were treated with TGF- $\beta 1$ (20, 40 and $100 \mathrm{mg} / \mathrm{ml}$ ), lenvatinib $(20,40$ and $100 \mathrm{mg} / \mathrm{ml})$ or dexamethasone $(20,40$ and $100 \mathrm{mg} / \mathrm{ml}$ plus TGF- $\beta 1$ (20, 40 and $100 \mathrm{mg} / \mathrm{ml})$ or PBS as a control. These concentrations were selected as they maximally inhibited cell growth, as confirmed as aforementioned. The viability of H1975 and H358 cells was examined using a Cell Counting kit-8 according to manufacturer's protocol (Dojindo Molecular Technologies, Inc., Kumamoto, Japan) following $12 \mathrm{~h}$.

Cell invasion and migration assays. H1975 cells were treated with TGF- $\beta 1$, lenvatinib or dexamethasone and PBS-treated cells were used as control. For the invasion assay, cells were suspended at a density of $1 \times 10^{5}$ in $500 \mu 1$ serum-free Dulbecco's modified Eagle's medium (Gibco; Thermo Fisher Scientific, Inc.). H1975 cells were treated with TGF- $\beta 1$, lenvatinib or dexamethasone and inserted into the top of a BD BioCoat Matrigel Invasion Chamber (BD Biosciences, Franklin Lakes, NJ, USA) according to the manufacturer's protocol. For the migration assay, $\mathrm{H} 1975$ cells were inoculated with TGF- $\beta 1$, lenvatinib or dexamethasone for $12 \mathrm{~h}$ at $37^{\circ} \mathrm{C}$ and a control insert (BD Biosciences) instead of a Matrigel Invasion Chamber. Cells were fixed with $4 \%$ paraformaldehyde for $30 \mathrm{~min}$ and then stained with $0.2 \%$ crystal violet for $30 \mathrm{~min}$ at $37^{\circ} \mathrm{C}$ (Sigma-Aldrich; Merck KGaA). The tumor cells that had successfully invaded and migrated were counted in at least three randomly selected stained-fields using light microscopy (Olympus BX51; Olympus Corporation, Tokyo, Japan) for each membrane at magnification, $\mathrm{x} 40$.

Scratch wound healing assays. H1975 and H358 cells were cultured in RPMI 1640 medium supplemented with $10 \%$ FBS until a 50-60\% monolayer of cells was observed in the culture dishes. A sterile pipette tip was scratched across the surface of the culture dish to disturb the monolayer. TGF- $\beta 1$ (20 ng/ml), dexamethasone $(20 \mu \mathrm{M})$ and combined treatment ( $20 \mathrm{ng} / \mathrm{ml} \mathrm{TGF}-\beta 1$ and $20 \mu \mathrm{M}$ dexamethasone) were added into the RPMI-1640 medium following surface scratching. Images of $\mathrm{H} 1975$ and $\mathrm{H} 358$ cells were captured $12 \mathrm{~h}$ post-treatment using a digital camera (DSC-RXO; Sony Corporation, Tokyo, Japan). ImageJ software (version 3.60; National Institutes of Health, Bethesda, MA, USA) was used to analyze the scratches. 
Table I. Sequences of primers used in the study.

\begin{tabular}{lll}
\hline Gene & \multicolumn{1}{c}{ Sequence reverse $\left(5^{\prime}-3^{\prime}\right)$} & Forward \\
\hline CYR61 & ATCGAGATCTGGAGAAGGCGGAG GGCGCGG & ATCGAGATCTAATGGAGCCAGGGGAGGCG \\
VEGFR1 & AAGAGAGCTTCCGTAAGGCG & GCATCCTCTTCAGTTACGTCC \\
VEGFR2 & GGAAGCTCCTGAAGATCTGT & GAGGATATTTCGTGCCGCGC \\
VEGFR3 & AGTCACACGTCATCGACACC & ATTGGGACAGCTTGGATCAC \\
FGFR1 & CACATCGAGGTGAACGGGAGTAAG & CGCATCCTCAAAGGAGACATTCC \\
FGFR2 & GGAAAGTGTGGTCCCATCTGA & TCCAGGTGGTACGTGTGATTG \\
FGFR3 & CATTGGAGGCATAAGCTG & AGCACGGTAACGTAGGGTGT \\
FGFR4 & GCAACTCCATCGGCCTTTCCTACCAG & AGAACCAGTGAGCCTGATACATACAG \\
Vimentin E-cadherin & TGGAGGAATTCTTGCTTTGC & CGTACATGTCAGCCAGCTTC \\
Slug & TATTTGGTTGGTCAGCACAGG & GACGCAATCAATGTTTACTCG \\
MMP-1 & TTCCACAGGTCCCACAAC & GCATTCCTCACAGCCAAC \\
MMP-9 & TGGGCTACGTGACCTATGACAT & GTATGGTCGTGGCTCTAAGC \\
CPI & GGGATTCCCTGGACCTAAAG & GGAACACCTCGCTCTCCA \\
Fibronectin & CCAGGCAGTACAATGTGGGT & TGGAATAGAGCTCCCAGGCT \\
Cytochalasin-D & GGTATTCAGCCAAACGACCA & CCTCTCACTCGGTTCTCGAT \\
G-actin & CCAGGGCTTTTCAAAAATGA & CCGATCCAATCTGTTCTGGT \\
$\beta$-actin & CGGAGTCAACGGATTTGGTC & AGCCTTCTCCATGGTCGTGA
\end{tabular}

MMP, matrix metalloproteinase; CPI, collagen type I; FGFR, fibroblast growth factor receptor; VEGFR, vascular endothelial growth factor receptor; CYR61, cysteine-rich angiogenic inducer 61.

Western blot analysis. $\mathrm{H} 1975$ and $\mathrm{H} 358$ cells were treated with lenvatinib (40 ng/ml), TGF- $\beta 1$ (40 ng/ml), dexamethasone $(20 \mu \mathrm{M})$ and combined treatment for $12 \mathrm{~h}$. H1975 and $\mathrm{H} 358$ cells were harvested by scraping, lysed in RIPA buffer and homogenized at $4^{\circ} \mathrm{C}$ for $10 \mathrm{~min}$. Proteins $(20 \mu \mathrm{g})$ were separated by $12 \%$ SDS-PAGE assays followed by transfer to polyvinylidene fluoride membranes (EMD Millipore Billerica, MA, USA). The membranes were blocked with $5 \%$ bovine serum albumin (Sigma-Aldrich; Merck KGaA) at $4^{\circ} \mathrm{C}$ for $12 \mathrm{~h}$ and then incubated with ERK (cat. no. ab196883), AKT (cat. no. ab8805), Snail (cat. no. ab180714), VEGFR1 (cat. no. ab36844), VEGFR2 (cat. no. ab2349), VEGFR3 (cat. no. ab27278), FGFR1-4 (cat. no. ab10646), FGFR2 (cat. no. ab10648), FGFR3 (cat. no. ab137084), FGFR4 (cat. no. ab178396),(all dilution 1:1,000) and $\beta$-actin (dilution 1:2,000; cat. no. ab8226) primary antibodies for $12 \mathrm{~h}$ at $4^{\circ} \mathrm{C}$. All primary antibodies were purchased from Abcam (Cambridge, MA, USA). The membranes were subsequently incubated with secondary rabbit anti-mouse antibodies (dilution 1:5,000; cat. no. PI-1000; Vector Laboratories, Inc.) for $2 \mathrm{~h}$ at $37^{\circ} \mathrm{C}$. Protein expression was analyzed using a biotin-labeled chemi-luminescence detection system (cat. no. Z370398; Sigma-Aldrich; Merck KGaA). Densitometric quantification of the immunoblot data was performed using Quantity-One 1.1 (Bio-Rad Laboratories, Inc.) software.

Apoptosis assay. $\mathrm{H} 1975\left(1 \times 10^{6}\right)$ and $\mathrm{H} 358\left(1 \times 10^{6}\right)$ cells were treated with lenvatinib (40 ng/ml), TGF- $\beta 1$ (40 ng/ml), dexamethasone $(20 \mu \mathrm{M})$ or combined treatment for $12 \mathrm{~h}$ at $37^{\circ} \mathrm{C}$. The cells were incubated with PBS and the apoptosis of the suspended cells was analyzed by flow cytometry. Cells were collected and suspended with Annexin V-FITC and PI (Annexin V-FITC/PI Apoptosis Detection kit; BD Biosciences) for $30 \mathrm{~min}$ at $4^{\circ} \mathrm{C}$ according to the manufacturer protocol. Fluorescence was measured using a fluorescence-activated cell sorting flow cytometer (FCS Express ${ }^{\mathrm{TM}} 4$ IVD, BD Biosciences) and analyzed using Quantity One software (version 3.0; Bio-Rad Laboratories, Inc.).

Animal study. A total of 80 specific pathogen-free female C57BL/6 (6-week-old; 26-32 g) mice were purchased from Shanghai SLAC Laboratory Animal Co., Ltd. (Shanghai, China). All mice were treated in accordance with the Guide for the Care and Use of Laboratory Animals of Tianjin Chest Hospital (Tianjin, China) and the study was approved by the Ethics Committee of Tianjin Chest Hospital (Tianjin, China). All mice were housed under controlled temperatures $\left(23 \pm 2^{\circ} \mathrm{C}\right)$ in $50 \%$ humidity, in a $12 \mathrm{~h}$ light/dark cycle with free access to food and water. Mice were subcutaneously implanted with H1975 tumor cells $\left(1 \times 10^{7}\right)$ using a syringe and divided into four groups ( $n=20$ per group). Treatment was initiated on day 7 following tumor implantation when the tumor diameter reached 5-6 mm. Xenograph mice were intravenously injected with $500 \mathrm{ng}$ lenvatinib, $500 \mathrm{ng}$ dexamethasone or synergistic treatment with PBS as control. Treatment was continued once a day for 14 days. Tumor volumes were calculated according to a previous study (25).

Statistical analysis. All data were presented as the mean \pm standard error of the mean from triplicate experiments. All data were analyzed using SPSS Statistics 19.0 (IBM Corp., Armonk, NY, USA). Unpaired data were determined by Student's t-test and comparisons of data between multiple groups were analyzed via analysis of variance. Kaplan-Meier was used to estimate the risk of relapse and re-treatment during 120-day treatment. 

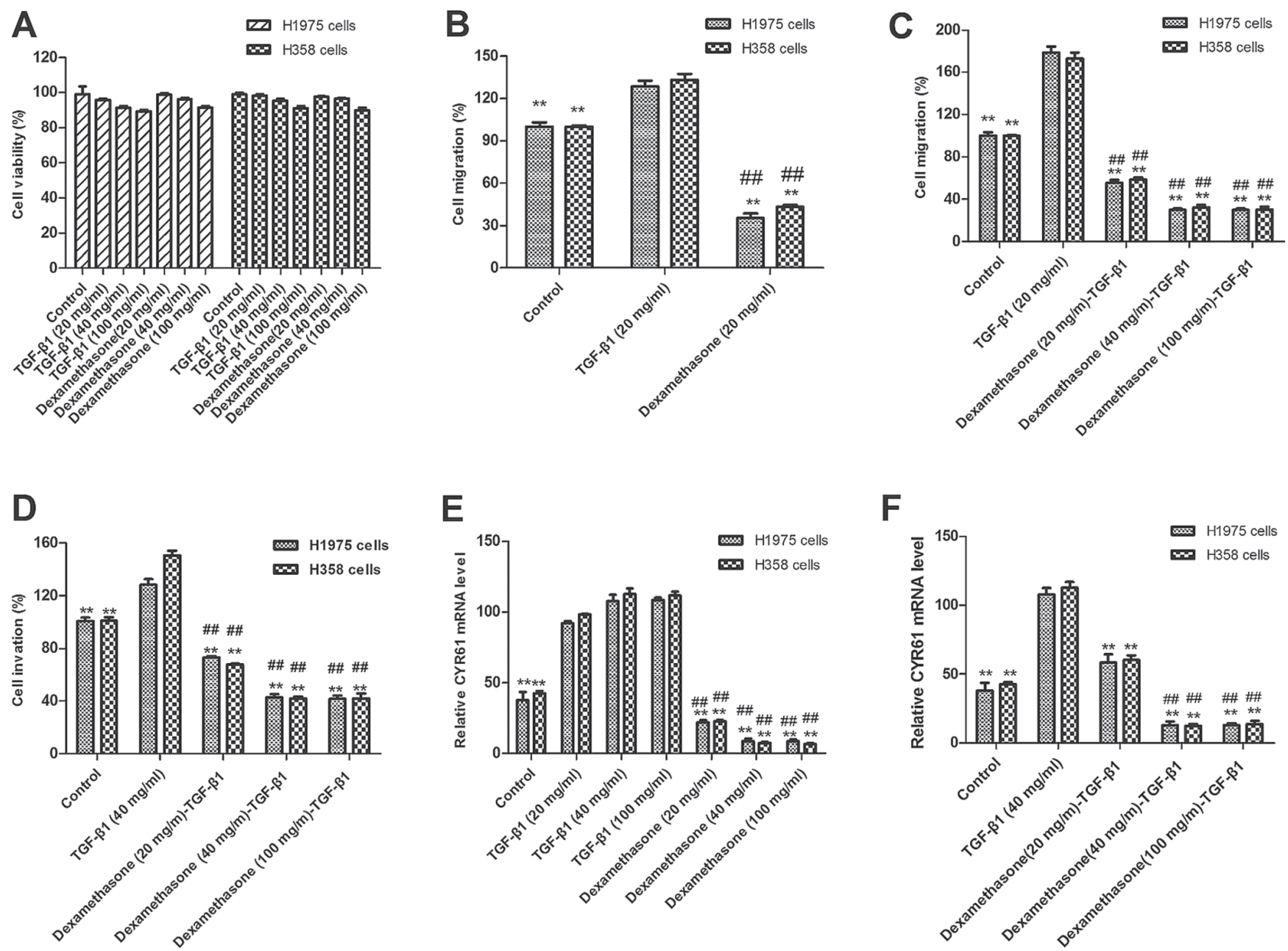

Figure 1. Effects of dexamethasone on TGF- $\beta 1$-induced migration and invasion in NSCLC. (A) Cell viabilities did not change in dexamethasone-treated and TGF- $\beta 1$-treated H1975 and H358 cells at different doses compared with the control. (B) TGF- $\beta 1$ promoted and dexamethasone inhibited migration of NSCLC H1975 and H358 cells following 12-h exposure compared with control cells. (C) Dexamethasone treatment eliminated the effect of TGF- $\beta 1$-induced promotion of migration at 20,40 and $100 \mathrm{mg} / \mathrm{ml}$ following 12-h exposure, as compared with untreated and TGF- $\beta 1$-treated cells. (D) TGF- $\beta 1$ promoted and dexamethasone inhibited the invasion of NSCLC H1975 and H358 cells at dose of $40 \mathrm{mg} / \mathrm{ml}$ following 12-h exposure compared with control cells. (E) Dexamethasone treatment eliminated the effect of TGF- $\beta 1$-induced promoted invasion at dose $>40$ and $100 \mathrm{mg} / \mathrm{ml}$ following 12-h exposure compared with untreated and TGF- $\beta 1$-treated cells. (F) TGF- $\beta 1$ enhanced CYR61 expression and dexamethasone inhibited CYR61 expression and reversed TGF- $\beta 1$-enhanced effects in NSCLC H1975 and H358 cells. ${ }^{* *} \mathrm{P}<0.01$ vs. the TGF- $\beta 1$ group; ${ }^{\# \#} \mathrm{P}<0.01$ vs. the control group. Data are presented as mean \pm standard error of the mean. TGF- $\beta 1$, transforming growth factor; NSCLC, non-small cell lung cancer; CRY61, cysteine-rich angiogenic inducer 61.

$\mathrm{P}<0.05$ was considered to represent statistically significant differences.

\section{Results}

Dexamethasone inhibits TGF- $\beta 1$ induced migration and invasion in NSCLC. It has been demonstrated that the expression of TGF- $\beta 1$ is associated with the prognosis of human cancer and TGF- $\beta 1$ enhanced CYR61 expression, which leads to the migration and invasion of tumor cells (26). Although the role of TGF- $\beta 1$ in NSCLC is not understood, dexamethasone has been demonstrated to inhibit migration and invasion in human colon cancer cells in a previous study (21). To investigate the suppressive effects of dexamethasone in human NSCLC H1975 and H358 cells, tumor cell viability and migration were evaluated via MTT and scratch-wound assays, respectively. The results in Fig. 1A indicate that there were changes in the viability of cells treated with TGF- $\beta 1$ and dexamethasone (20, 40 and $100 \mathrm{mg} / \mathrm{ml}$ ) compared with non-treated control cells. As presented in Fig. 1B, dexamethasone treatment $(20 \mathrm{mg} / \mathrm{ml})$ significantly suppressed H1975 and H358 cell migration following 12-h exposure, as compared with untreated and TGF- $\beta 1$-treated cells $(\mathrm{P}<0.01)$. The results revealed that $20 \mathrm{mg} / \mathrm{ml}$ of TGF- $\beta 1$ and $20 \mathrm{mg} / \mathrm{ml}$ of dexamethasone exhibited the maximal inhibitory effect on H1975 and H358 cells. Therefore, $20 \mathrm{mg} / \mathrm{ml}$ of TGF- $\beta 1$ in combination with $20 \mathrm{mg} / \mathrm{ml}$ of dexamethasone was selected as the final dose.

Notably, migration data also demonstrated that TGF- $\beta$ promoted the migration and invasion of NSCLC H1975 and $\mathrm{H} 358$ cells. As presented in Fig. 1C, 20 ng/ml TGF- $\beta 1$ significantly enhanced the migration of $\mathrm{H} 1975$ and $\mathrm{H} 358$ cells, as compared with control cells $(\mathrm{P}<0.01)$. By contrast, dexamethasone $(20 \mathrm{mg} / \mathrm{ml})$ significantly inhibited the migration of H1975 and H358 cells when administered with $20 \mathrm{ng} / \mathrm{ml}$ TGF- $\beta 1(\mathrm{P}<0.01)$.

In order to confirm the effects of dexamethasone on the migration of H1975 cells, Transwell assays were used to further assess the invasion of H1975 and H358 cells. The results 

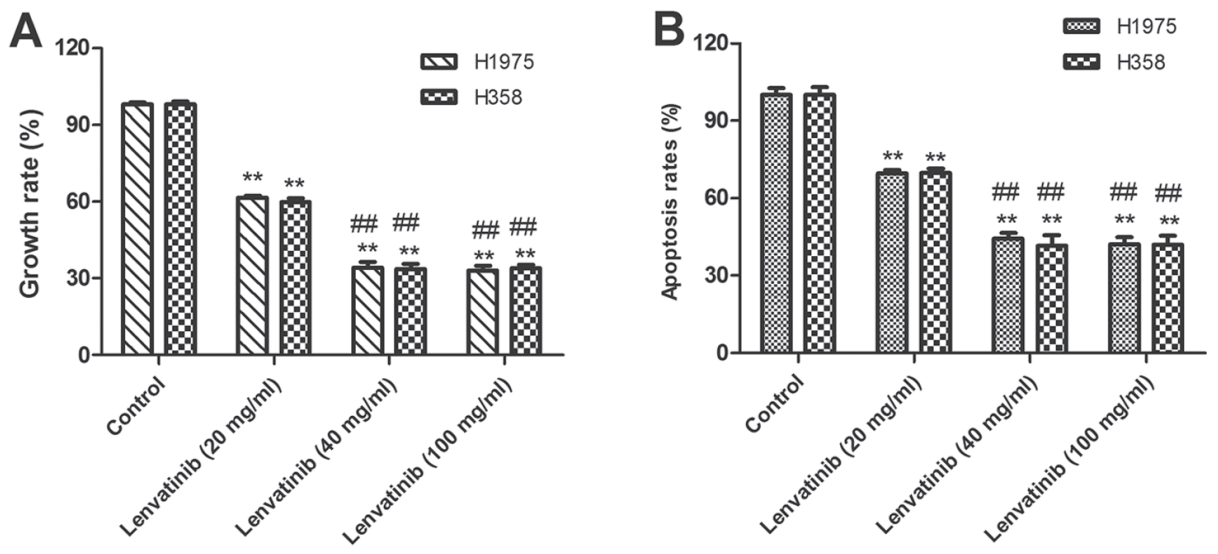

$\mathbf{E}$
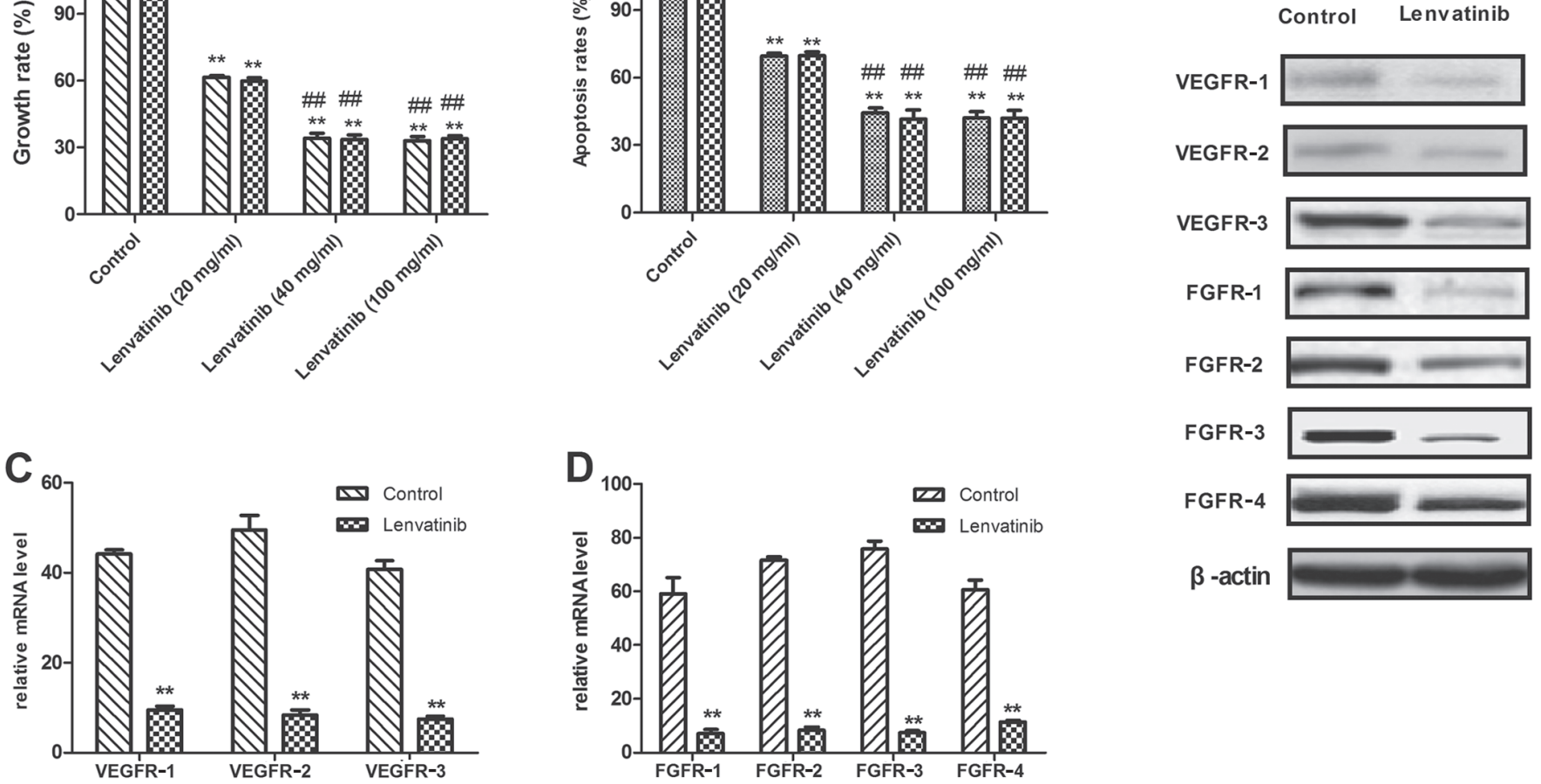

Figure 2. Lenvatinib inhibited tumor growth of NSCLC and downregulated VEGFR and FGFR. (A) Treatment with 20, 40 and $100 \mathrm{mg} / \mathrm{ml}$ lenvatinib (A) significantly inhibited the growth of H1975 and H358 cells and (B) significantly induced the apoptosis of H1975 and H358 cells following 48-h treatment compared with control cells. (C) Treatment with $40 \mathrm{mg} / \mathrm{ml}$ lenvatinib downregulated VEGFR1-3 expression in H1975 cells compared with untreated controls. (D) Treatment with $40 \mathrm{mg} / \mathrm{ml}$ lenvatinib downregulated FGFR1-4 expression in H1975 cells compared untreated control. (E) Treatment with $40 \mathrm{mg} / \mathrm{ml}$ lenvatinib downregulated protein expression of VEGFR1-3 and FGFR1-4 in H1975 cells compared with untreated controls. ${ }^{* *} \mathrm{P}<0.01 \mathrm{vs}$. control; ${ }^{\# \#} \mathrm{P}<0.01 \mathrm{vs}$. lenvatinib $20 \mathrm{mg} / \mathrm{ml}$. Data are presented as mean \pm standard error of the mean. NSCLC, non-small cell lung cancer; VEGFR, vascular endothelial growth factor receptor; FGFR, fibroblast growth factor receptor.

in Fig. 1D indicate that dexamethasone significantly inhibited the tumor cell invasion induced by TGF- $\beta 1(\mathrm{P}<0.01)$. In conclusion, these results suggest that dexamethasone not only affects tumor cell viability but also inhibits TGF- $\beta 1$-dependent tumor cell migration and invasion. To investigate the influence of dexamethasone on tumor cell migration through CYR61 modulation, CYR61 was analyzed. The results in Fig. 1E and F indicate that CYR61 expression was significantly increased following treatment with TGF- $\beta 1$ and significantly decreased following dexamethasone treatment $(\mathrm{P}<0.01)$.

Lenvatinib suppresses the growth of NSCLC by binding with VEGFR1-3. Lenvatinib was reported to be an adjuvant therapy combined with carboplatin and paclitaxel in patients with NSCLC (14). In order to analyze the cell-killing effects of lenvatinib, the current study used an MTT assay to assess the inhibitory effects on the viability of $\mathrm{H} 1975$ and H358 cells. In Fig. 2A, growth of H1975 and H358 cells is demonstrated to be inhibited following treatment with $40 \mathrm{mg} / \mathrm{ml}$ lenvatinib for $48 \mathrm{~h}$. It was also demonstrated that lenvatinib at a concentration of $>40 \mathrm{mg} / \mathrm{ml}$ was enough to inhibit tumor cell growth. For further analysis, the apoptosis of two human NSCLC cell lines, H1975 and H358, was examined by FACS following lenvatinib treatment FACS. As presented in Fig. 2B, the apoptosis rate of H1975 and H358 was significantly decreased following treatment with lenvatinib at a concentration of $40 \mathrm{mg} / \mathrm{ml}$ compared with a concentration of $10 \mathrm{mg} / \mathrm{ml}$. It was also observed that a lenvatinib dose $\geq 20 \mathrm{mg} / \mathrm{ml}$ was enough to significantly reduce the rate of apoptosis in H1975 and H358 cells compared with the untreated control.

Previous reports indicate that treatment with lenvatinib exhibited an effective outcome in patients with cancer (14). However, few studies analyzing the use of lenvatinib for NSCLC have been completed $(14,27)$. In the current study, the expression of VEGFR1-3 and FGFR1-4 protein in H1975 and H358 was analyzed, compared with normal lung cells. As presented in Fig. 2C, the mRNA expression level of VEGFR1-3 in control H1975 cells was significantly higher than lenvatinib-treated cells $(\mathrm{P}<0.01)$. RT-qPCR demonstrated that FGFR1-4 mRNA expression was significantly decreased in lenvatinib-treated H1975 cells compared with the non-treated control (Fig. 2D; $\mathrm{P}<0.01)$. The results in Fig. 2E demonstrated that VEGFR1-3 protein expression was decreased in lenvatinib-treated H1975 cells compared with untreated cells. These results indicated that the growth of H1975 and H358 cells was suppressed following treatment with lenvatinib.

Dexamethasone inhibits the epithelial-mesenchymal transition (EMT) process via the AKT/ERK signaling pathways. In consideration of the inhibitive effects of dexamethasone on TGF- $\beta 1$-induced cell migration and invasion, the present study hypothesized that the TGF- $\beta 1$-induced EMT signal pathway was inhibited by dexamethasone. Therefore, the underlying mechanism of dexamethasone on the expression of important 

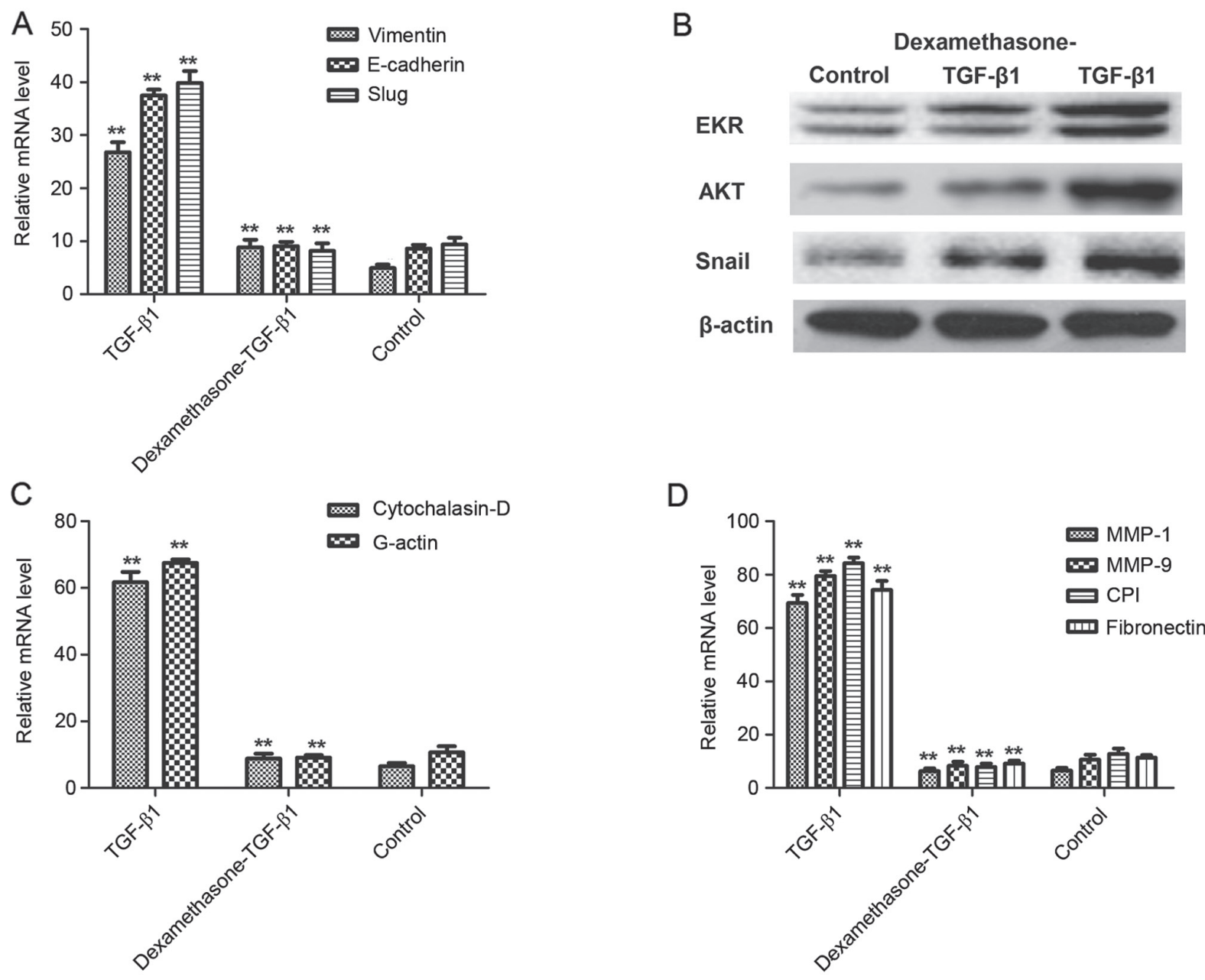

Figure 3. Dexamethasone inhibited the EMT process via the AKT/ERK signaling pathways. (A) TGF- $\beta 1$ increased the mRNA expression of Vimentin, E-cadherin and Slug, and dexamethasone eliminated increasing expression in H1975 cells. (B) TGF- $\beta 1$ upregulated protein expression of EKR, AKT and Snail and dexamethasone eliminated increasing expression in H1975 cells. (C) TGF- $\beta 1$ increased Cytochalasin-D and G-actin but dexamethasone canceled-out this effect of regulation. (D) Migration-related MMP-1, MMP-9, CPI and fibronectin expression were increased following treatment with TGF- $\beta 1$ and this was canceled-out by $40 \mathrm{mg} / \mathrm{ml}$ dexamethasone. ${ }^{* *} \mathrm{P}<0.01 \mathrm{vs}$. control. Data are presented as mean \pm standard error of the mean. EMT, epithelial-mesenchymal transition; AKT, protein kinase B; ERK, extracellular signal-regulated kinases; TGF- $\beta 1$, transforming growth factor- $\beta 1$; MMP, matrix metalloproteinase; CPI, collagen type I.

EMT markers, including Vimentin, E-cadherin and Slug was assessed. The results in Fig. 3A demonstrate that the expression levels of Vimentin, E-cadherin and Slug were significantly elevated when treated with TGF- $\beta 1$ in H1975 cells, whereas dexamethasone significantly decreased this elevated expression $(\mathrm{P}<0.01)$, compared with a control. Furthermore, to confirm that dexamethasone inhibited the EMT process via the AKT/ERK signaling pathway, protein expression of EKR, AKT and Snail induced by TGF- $\beta$ was markedly promoted and eliminated this effect following dexamethasone treatment (Fig. 3B).

A previous study indicated that degradation of the extracellular matrix (ECM) by MMP proteins is associated with tumor cell migration (28). The results presented in Fig. 3C indicate that Cytochalasin-D and G-actin were significantly upregulated in TGF- $\beta 1$-treated tumor cells, whereas dexamethasone canceled-out this effect $(\mathrm{P}<0.01)$, compared with a control. However, the expression levels of MMP-1, MMP-9, collagen type I and fibronectin, which are important ECM proteins with a vital role in cell migration, were enhanced following TGF- $\beta 1$ treatment and were significantly decreased after treatment with TGF- $\beta 1$ and dexamethasone in H1975 cells, compared with a control $(\mathrm{P}<0.01$; Fig. 3D). These results suggested that dexamethasone suppressed the migration-promoting proteins and promoted the migration-inhibiting proteins in TGF- $\beta 1$-induced EMT process, which may be beneficial in the treatment of cancer cell migration and invasion in the EKR/AKT pathway.

Efficacy of synergistic treatment of dexamethasone and lenvatinib in NSCLC-bearing mice. To investigate whether the synergistic treatment of dexamethasone and lenvatinib are effective agents for NSCLC in vivo, NSCLC-bearing mice were established for further analysis. The anti-tumor efficacy of dexamethasone and lenvatinib was assessed in the NSCLC mouse model. As presented in Fig. 4A, tumor size was significantly inhibited in xenograph mice treated with dexamethasone and lenvatinib compared with the mice treated with PBS or a single agent $(\mathrm{P}<0.01)$. In addition, 120-day long-term survival analysis revealed that the combined treatment of dexamethasone and lenvatinib significantly increased the survival rate compared with single dexamethasone or lenvatinib treatment (Fig. 4B). As expected, the results in Fig. 4B demonstrated that synergistic 

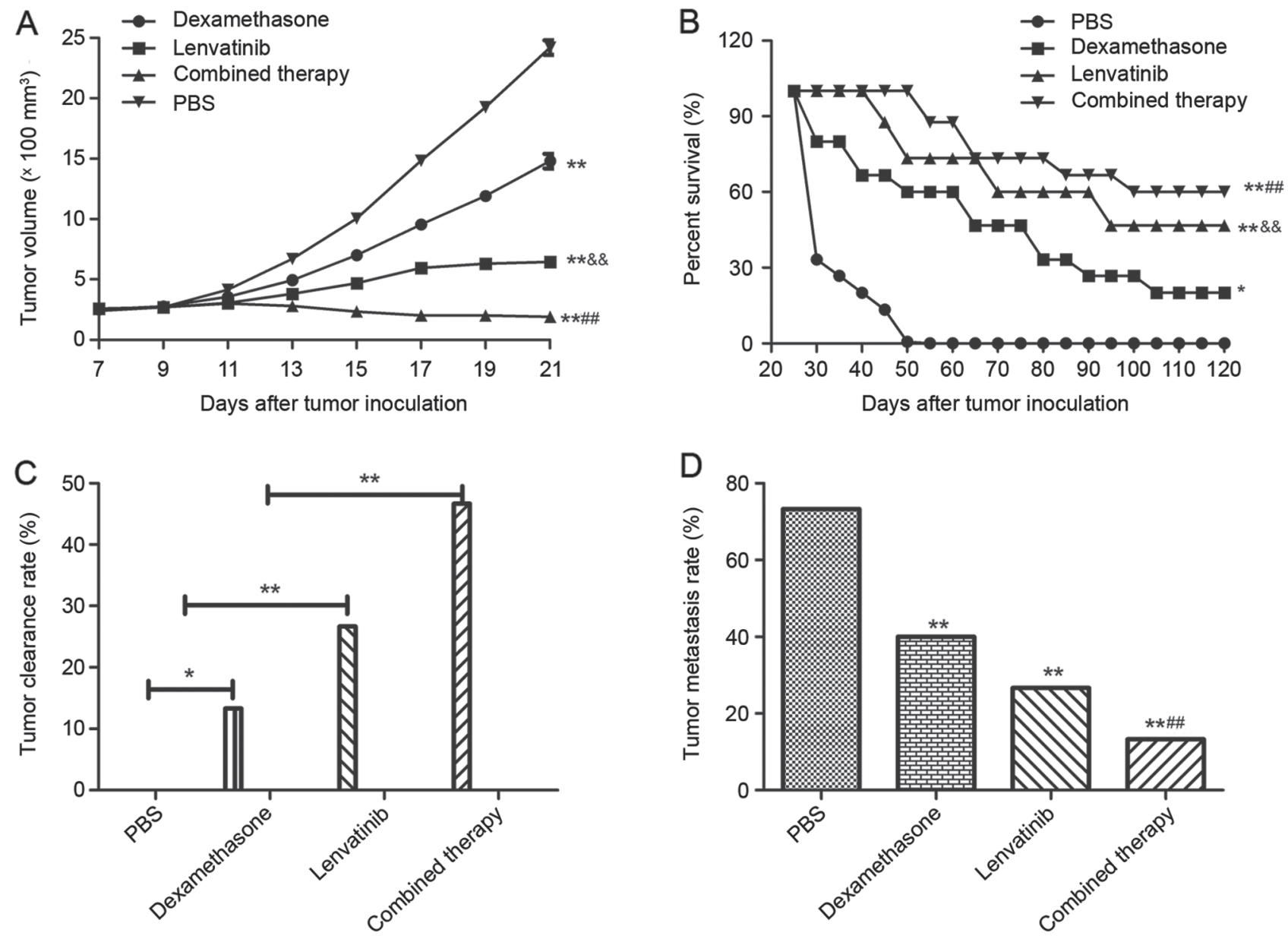

Figure 4. Dexamethasone and lenvatinib demonstrated beneficial therapeutic and inhibitory migration effects in NSCLC-bearing mice. (A) Dexamethasone and lenvatinib presented an effective cooperative treatment for NSCLC-bearing mice compared with single agent and control treatments. (B) Survival time was prolonged following cooperative treatment of dexamethasone and lenvatinib during 120-day observation compared with single agent and control treatments. (C) Combined treatment of dexamethasone and lenvatinib enhanced tumor clearance rate for NSCLC-bearing mice compared with single agent and control treatments. (D) Tumor metastasis rate was limited following treatment with dexamethasone and lenvatinib in a 120-day observation period compared with single agent and control treatments ( $\mathrm{n}=15$ in each experimental group). ${ }^{*} \mathrm{P}<0.05$ and ${ }^{* * *} \mathrm{P}<0.01$ vs. the PBS control group; and ${ }^{\text {\&\&}} \mathrm{P}<0.01$ vs. the dexamethasone ${ }^{\#} \mathrm{P}<0.01$ vs. the lenvatinib or dexamethasone group. NSCLC, non-small cell lung cancer; PBS, phosphate-buffered saline.

treatment ( $\mathrm{n}=15$ in each group) prolonged the survival of NSCLC-bearing mice compared with single agent and control mice. Fig. 4C also indicated that synergistic treatment of dexamethasone and lenvatinib against NSCLC was effective enough to partially protect the animals and significantly increased the percentage of tumors eliminated in the combined treatment group compared with the dexamethasone, lenvatinib and PBS groups, which translated into long-term survival and tumor-free living. Furthermore, Fig. 4D indicates that the inhibition of tumor metastasis in NSCLC-bearing mice was significantly increased in the combined therapy group compared with the dexamethasone, lenvatinib and PBS groups $(\mathrm{P}<0.01)$. Results showed that combined therapy group demonstrated significant difference compared to dexamethasone or lenvatinib group $(\mathrm{P}<0.01)$. However, there was no significant difference between the dexamethasone group and the lenvatinib group.

\section{Discussion}

An increased occurrence of cancer has been associated with industrial pollution and destruction of the ecological environment in the last century (29). The increased rate of morbidity and mortality from lung cancer has become a particular problem and an increase in diagnosis has occurred in recent years (30). NSCLC is the type of primary lung cancer and is difficult to detect in the early stages. Thus, the majority of NSCLC patients are diagnosed with advanced stage lung cancer (31). As conventional radiation and chemotherapy exhibits little efficacy for NSCLC, more frequent recurrence and metastasis has occurred. In addition, a poor survival rate $(<15 \%)$ of patients with NSCLC was determined in over a 5 -year observation (32). Therefore, investigating novel agents to target metastasis-promoting factors has become a focus for the treatment of patients with NSCLC.

A previous study reported that CYR61 regulated migration in the EMT process and induced apoptosis in various cancer cells (33). In addition, CYR61 mediated Src signaling in triple negative breast cancer cells and was modulated by phosphoinositide 3-kinase/AKT signaling in prostate cancer $(34,35)$. TGF- $\beta 1$ has been demonstrated to upregulate CYR61 expression, which leads to migration and invasion in colon cancer cells and osteosarcoma cells $(21,36)$. In the current study, CYR61 expression was demonstrated to be superfluous in H1975 and H358 cells compared with normal lung cells. The CYR61 
signaling pathway was indispensable in the EMT process. In addition, dexamethasone inhibited TGF- $\beta 1$-induced CYR61 expression and regulated $\mathrm{N}$-cadherin, fibronectin, vimentin and E-cadherin expression, which was similar to a previous study (21). Furthermore, dexamethasone treatment significantly suppressed $\mathrm{H} 1975$ cells migration at dose of $20 \mu \mathrm{M}$ following 12-h exposure compared with untreated cells in vitro and inhibited tumor metastasis in xenograph mice in vivo.

Evidence of targeting VEGF-mediated pathways in a number of cancer tissues or tumors has demonstrated available treatment options $(15,37,38)$. Lenvatinib is a multi targeted anti-cancer target-therapeutic drug and studies have demonstrated that it is an efficient anticancer agent in patients with advanced solid tumors (39). However, single-agent therapy has to improve targeted treatment to overcome a low response rate and metastasis for patients with cancer (40). Therefore, combined treatment may be an ideal therapeutic regimen. In the current study, VEGFR1-3 and FGFR1-4 expression was detected and cytotoxic effects on H1975 and H358 cells were assessed. Notably, the migration of H1975 and H358 cells was observed to be suppressed following treatment with lenvatinib in vitro and in vivo.

Preclinical observation with combination therapy conferred relative advantages to single drug treatment and further study is required to evaluate the overall efficacy (41). The current exploratory analysis of tumor treatment and long-term survival indicated that treatment with lenvatinib and dexamethasone once daily exhibited a clear tumor regression and resulted in a survival rate of $80 \%$ in a 120 -day period in xenograph mice. Furthermore, the median metastasis-limit survival during 120-day observation in NSCLC mice model reached $66.67 \%$. The results of the current study indicated that synergistic treatment of dexamethasone and lenvatinib against NSCLC is effective enough to partially protect the animals and eliminate the tumors in experimental mice, which translated into long-term survival and tumor-free living.

In conclusion, two anticancer agents, dexamethasone and lenvatinib, were administered once daily in the present study. Notably, the data is suggestive of a NSCLC mice model, although dexamethasone downregulated the expression of EKR and AKT, and lenvatinib downregulated VEGFR and FGFR, which led to the reversal of TGF- $\beta 1$-induced cell migration. Dexamethasone and lenvatinib inhibited the migration and invasion of NSCLC by regulating the EKR/AKT and VEGF signal pathways. The current study suggests that the beneficial effects of cellular targeted therapy may further elucidate the mechanisms and this regimen is clinically applicable, but requires further study.

\section{Acknowledgements}

Not applicable.

\section{Funding}

No funding was received.

\section{Availability of data and materials}

The analyzed data sets generated during the study are available from the corresponding author on reasonable request.

\section{Authors' contributions}

DZ designed and wrote this study. YZ analyzed data and prepared the materials. ZC conducted some of the experiments. YT and $\mathrm{ZH}$ conducted the data analysis and experimental design, and proofed this manuscript.

\section{Ethics approval and consent to participate}

The animal use protocol was approved by the Committee on the Ethics of Animal Experiments of Tianjin Chest Hospital.

\section{Patient consent for publication}

Not applicable.

\section{Competing interests}

All authors declare that they have no competing interests.

\section{References}

1. Fenton-Ambrose L and Kazerooni EA: Preventative care: Lung-cancer screens now worth the cost. Nature 514: 35, 2014.

2. Kong R, Feng J, Ma Y, Zhou B, Li S, Zhang W, Jiang J, Zhang J, Qiao Z, Zhang T, et al: Silencing NACK by siRNA inhibits tumorigenesis in non-small cell lung cancer via targeting Notch1 signaling pathway. Oncol Rep 35: 2306-2314, 2016.

3. Brody H: Lung cancer. Nature 513: S1, 2014.

4. Moro-Sibilot D, Smit E, de Castro Carpeño J, Lesniewski-Kmak K, Aerts JG, Villatoro R, Kraaij K, Nacerddine K, Dyachkova Y, Smith KT, et al: Non-small cell lung cancer patients with brain metastases treated with first-line platinum-doublet chemotherapy: Analysis from the European FRAME study. Lung Cancer 90: 427-432, 2015.

5. Barnett SA, Downey RJ, Zheng J, Plourde G, Shen R, Chaft J, Akhurst T, Park BJ and Rusch VW: Utility of routine PET imaging to predict response and survival after induction therapy for non-small cell lung cancer. Ann Thorac Surg 101: 1052-1059, 2016

6. Xie FJ, Lu HY, Zheng QQ, Qin J, Gao Y, Zhang YP, Hu X and Mao WM: The clinical pathological characteristics and prognosis of FGFR1 gene amplification in non-small-cell lung cancer: A meta-analysis. Onco Targets Ther 9: 171-181, 2016.

7. Lim SH, Sun JM, Lee SH, Ahn JS, Park K and Ahn MJ: Pembrolizumab for the treatment of non-small cell lung cancer. Expert Opin Biol Ther 16: 397-406, 2016.

8. Müller B, Bovet M, Yin Y, Stichel D, Malz M, González-Vallinas M, Middleton A, Ehemann V, Schmitt J, Muley $\mathrm{T}$, et al: Concomitant expression of far upstream element (FUSE) binding protein (FBP) interacting repressor (FIR) and its splice variants induce migration and invasion of non-small cell lung cancer (NSCLC) cells. J Pathol 237: 390-401, 2015

9. Zhao Q, Yue J, Zhang C, Gu X, Chen $\mathrm{H}$ and Xu L: Inactivation of $\mathrm{M} 2 \mathrm{AChR} / \mathrm{NF}-\kappa \mathrm{B}$ signaling axis reverses epithelial-mesenchymal transition (EMT) and suppresses migration and invasion in non-small cell lung cancer (NSCLC). Oncotarget 6: 29335-29346, 2015.

10. Zhang H, Zhu X, Li N, Li D, Sha Z, Zheng X and Wang H: miR-125a-3p targets MTA1 to suppress NSCLC cell proliferation, migration, and invasion. Acta Biochim Biophys Sin (Shanghai) 47: 496-503, 2015

11. Roth MT, Ivey JL, Esserman DA, Crisp G, Kurz J and Weinberger M: Individualized medication assessment and planning: Optimizing medication use in older adults in the primary care setting. Pharmacotherapy 33: 787-797, 2013.

12. Solimando DA Jr and Waddell JA: Lenvatinib and palbociclib. Hosp Pharm 50: 578-582, 2015.

13. Oikonomopoulos G, Aravind P and Sarker D: Lenvatinib: A potential breakthrough in advanced hepatocellular carcinoma? Future Oncol 12: 465-476, 2016. 
14. Nishio M, Horai T, Horiike A, Nokihara H, Yamamoto N, Takahashi T, Murakami H, Yamamoto N, Koizumi F, Nishio K, et al: Phase 1 study of lenvatinib combined with carboplatin and paclitaxel in patients with non-small-cell lung cancer. Br J Cancer 109: 538-544, 2013.

15. Hutson TE: Targeted therapies for the treatment of metastatic renal cell carcinoma: Clinical evidence. Oncologist 16 (Suppl 2): S14-S22, 2011.

16. Matsui J and Funahashi Y: Preclinical biomarker research and patient stratification of molecular target agents: The anti-angiogenic inhibitor Lenvatinib mesylate (E7080). Nihon Yakurigaku Zasshi 142: 162-166, 2013.

17. Okamoto K, Kodama K, Takase K, Sugi NH, Yamamoto Y, Iwata $\mathrm{M}$ and Tsuruoka A: Antitumor activities of the targeted multi-tyrosine kinase inhibitor lenvatinib (E7080) against RET gene fusion-driven tumor models. Cancer Lett 340: 97-103, 2013

18. Kuznar W: Lenvatinib extends survival in metastatic renal-cell carcinoma. Am Health Drug Benefits 8: 18, 2015 (In Japanese).

19. Molina AM, Hutson TE, Larkin J, Gold AM, Wood K, Carter D, Motzer R and Michaelson MD: A phase 1b clinical trial of the multi-targeted tyrosine kinase inhibitor lenvatinib (E7080) in combination with everolimus for treatment of metastatic renal cell carcinoma (RCC). Cancer Chemother Pharmacol 73: 181-189, 2014.

20. Berdeja J, Jagannath S, Zonder J, Badros A, Kaufman JL, Manges R, Gupta M, Tendolkar A, Lynch M, Bleickardt E, et al: Pharmacokinetics and safety of elotuzumab combined with lenalidomide and dexamethasone in patients with multiple myeloma and various levels of renal impairment: Results of a phase Ib study. Clin Lymphoma Myeloma Leuk 16: 129-138, 2016

21. Han S, Bui NT, Ho MT, Kim YM, Cho M and Shin DB: Dexamethasone inhibits TGF- $\beta 1$-induced cell migration by regulating the ERK and AKT pathways in human colon cancer cells via CYR61. Cancer Res Treat 48: 1141-1153, 2016.

22. Chijiiwa M, Mochizuki S, Kimura T, Abe H, Tanaka Y, Fujii Y, Shimizu H, Enomoto H, Toyama Y and Okada Y: CCN1 (Cyr61) is overexpressed in human osteoarthritic cartilage and inhibits ADAMTS-4 (Aggrecanase 1) activity. Arthritis Rheumatol 67: $1557-1567,2015$.

23. Grazioli S, Gil S, An D, Kajikawa O, Farnand AW, Hanson JF Birkland T, Chen P, Duffield J, Schnapp LM, et al: CYR61 (CCN1) overexpression induces lung injury in mice. Am J Physiol Lung Cell Mol Physiol 308: L759-L765, 2015.

24. Zhuang T, Djemil T, Qi P, Magnelli A, Stephans K, Videtic G and Xia P: Dose calculation differences between Monte Carlo and pencil beam depend on the tumor locations and volumes for lung stereotactic body radiation therapy. J Appl Clin Med Phys 14: 4011, 2013.

25. Livak KJ and Schmittgen TD: Analysis of relative gene expression data using real-time quantitative PCR and the 2(-Delta Delta C(T)) method. Methods 25: 402-408, 2001

26. Huang YT, Lan Q, Ponsonnet L, Blanquet M, Christofori G, Zaric J and Rüegg C: The matricellular protein CYR61 interferes with normal pancreatic islets architecture and promotes pancreatic neuroendocrine tumor progression. Oncotarget 7: 1663-1674, 2016.

27. Nagashima S, Matsuo S, Takahashi M, Umemoto Y, Hirano T, Enomoto K, Sakurai K and Amano S: Effectiveness of lenvatinib for thyroid cancer with lung metastases-report of a case. Gan To Kagaku Ryoho 43: 2121-2123, 2016 (In Japanese).

28. Li Z, Xu X, Bai L, Chen W and Lin Y: Epidermal growth factor receptor-mediated tissue transglutaminase overexpression couples acquired tumor necrosis factor-related apoptosis-inducing ligand resistance and migration through c-FLIP and MMP-9 proteins in lung cancer cells. J Biol Chem 286: 21164-21172, 2011.
29. Lee YT, Liu CJ, Hu YW, Teng CJ, Tzeng CH, Yeh CM, Chen TJ, Lin JK, Lin CC, Lan YT, et al: Incidence of second primary malignancies following colorectal cancer: A distinct pattern of occurrence between colon and rectal cancers and association of co-morbidity with second primary malignancies in a population-based cohort of 98,876 patients in Taiwan. Medicine (Baltimore) 94: e1079, 2015.

30. Charvat H, Sasazuki S, Inoue M, Iwasaki M, Sawada N, Shimazu T, Yamaji T and Tsugane S; JPHC Study Group: Prediction of the 10-year probability of gastric cancer occurrence in the Japanese population: The JPHC study cohort II. Int J Cancer 138: 320-331, 2016.

31. Kim DS, Park KM, Won YS, Kim JY, Lee JK, Kim JG, Oh ST, Jung SS and Kang WK: Occurrence and prognosis of symptomatic venous thromboembolism in colorectal cancer surgery patients. Vasc Specialist Int 30: 49-55, 2014.

32. Gold M, Dunn LB, Phoenix B, Paul SM, Hamolsky D, Levine JD and Miaskowski C: Co-occurrence of anxiety and depressive symptoms following breast cancer surgery and its impact on quality of life. Eur J Oncol Nurs 20: 97-105, 2016.

33. Zhu X, Song Y, Huo R, Zhang J, Sun S, He Y, Gao H, Zhang M, Sun X, Zhai T, et al: Cyr61 participates in the pathogenesis of rheumatoid arthritis by promoting proIL-1 $\beta$ production by fibroblast-like synoviocytes through an AKT-dependent NF- $\kappa \mathrm{B}$ signaling pathway. Clin Immunol 157: 187-197, 2015

34. Sánchez-Bailón MP, Calcabrini A, Mayoral-Varo V, Molinari A, Wagner KU, Losada JP, Ciordia S, Albar JP and Martín-Pérez J: Cyr61 as mediator of Src signaling in triple negative breast cancer cells. Oncotarget 6: 13520-13538, 2015.

35. Lee YJ, Lee DM and Lee SH: Production of Cyr61 protein is modulated by extracellular acidification and PI3K/Akt signaling in prostate carcinoma PC-3 cells. Food Chem Toxicol 58: 169-176, 2013.

36. Chen J, Song Y, Yang J, Gong L, Zhao P, Zhang Y and Su H: The up-regulation of cysteine-rich protein 61 induced by transforming growth factor beta enhances osteosarcoma cell migration. Mol Cell Biochem 384: 269-277, 2013.

37. Villanueva MT: Targeted therapies: Congratulations, you are still in the running towards becoming ovarian-next-top treatment. Nat Rev Clin Oncol 8: 570, 2011

38. Ngeow J, Tan IB and Choo SP: Targeted therapies in the treatment of gastric cancer. Asia Pac J Clin Oncol 7: 224-235, 2011.

39. Boss DS, Glen H, Beijnen JH, Keesen M, Morrison R, Tait B, Copalu W, Mazur A, Wanders J, O'Brien JP, et al: A phase I study of E7080, a multitargeted tyrosine kinase inhibitor, in patients with advanced solid tumours. Br J Cancer 106: 1598-1604, 2012.

40. Tsuruoka A, Matsui J, Suzuki T, Koyama N, Watanabe T and Funahashi Y: Preclinical and clinical researches of lenvatinib mesylate (Lenvima capsule), a novel antitumor agent approved for thyroid cancer treatment. Nihon Yakurigaku Zasshi 146: 283-290, 2015 (In Japanese).

41. Nakagawa T, Matsushima T, Kawano S, Nakazawa Y, Kato Y, Adachi Y, Abe T, Semba T, Yokoi A, Matsui J, et al: Lenvatinib in combination with golvatinib overcomes hepatocyte growth factor pathway-induced resistance to vascular endothelial growth factor receptor inhibitor. Cancer Sci 105: 723-730, 2014. 